Projets

de paysage

\section{Projets de paysage}

Revue scientifique sur la conception et l'aménagement de l'espace

$5 \mid 2011$

Le jardin et ses rapports à l'art. Encadrer, décadrer, recadrer

\title{
Michel Corajoud, Le Paysage, c'est l'endroit où le ciel et la terre se touchent
}

Note de lecture

Michel Corajoud, Le Paysage, c'est l'endroit où le ciel et la terre se

touchent - Reading report

\section{Sonia Keravel}

\section{OpenEdition}

\section{Journals}

\section{Édition électronique}

URL : https://journals.openedition.org/paysage/22304

DOI : $10.4000 /$ paysage. 22304

ISSN : 1969-6124

\section{Éditeur :}

École nationale supérieure du paysage de Versailles-Marseille, Institut national des sciences appliquées Centre Val de Loire - École de la nature et du paysage, École nationale supérieure d'architecture et de paysage de Bordeaux, École nationale supérieure d'architecture et de paysage de Lille, Agrocampus Angers

\section{Référence électronique}

Sonia Keravel, « Michel Corajoud, Le Paysage, c'est l'endroit où le ciel et la terre se touchent », Projets de paysage [En ligne], 5 | 2011, mis en ligne le 19 janvier 2011, consulté le 16 octobre 2021. URL : http:// journals.openedition.org/paysage/22304; DOI : https://doi.org/10.4000/paysage.22304

Ce document a été généré automatiquement le 16 octobre 2021.

\section{c) (i) $९$}

La revue Projets de paysage est mise à disposition selon les termes de la Licence Creative Commons Attribution - Pas d'Utilisation Commerciale - Pas de Modification 4.0 International. 


\title{
Michel Corajoud, Le Paysage, c'est l'endroit où le ciel et la terre se touchent
}

\author{
Note de lecture \\ Michel Corajoud, Le Paysage, c'est l'endroit où le ciel et la terre se \\ touchent - Reading report
}

Sonia Keravel

\section{RÉFÉRENCE}

Michel Corajoud, Le Paysage, c'est l'endroit où le ciel et la terre se touchent, Arles/Versailles, Actes Sud/ENSP, 2010, $272 \mathrm{p}$.

1 Dix ans après la monographie des éditions Hartmann ${ }^{1}$, les éditions Actes sud/ENSP publient un recueil réunissant l'ensemble des textes de Michel Corajoud. Ce regroupement d'essais épars, écrits à différentes époques, est tout à fait le bienvenu à un moment où la question de l'articulation entre pratique du projet de paysage et recherche se pose avec de plus en plus d'insistance. La réunion de ces textes laisse voir, en effet, la régularité avec laquelle Michel Corajoud a toujours tenté de théoriser sa pratique professionnelle pour pouvoir la transmettre et la partager.

2 Le titre reprend un essai de définition de la notion de paysage que l'auteur avait donné dans un livre marquant le renouveau de la pensée paysagère: Mort du paysage? Philosophie et Esthétique du paysage ${ }^{2}$. Mais plus qu'une définition du paysage, l'ensemble de ces textes nous renseigne surtout sur la définition du métier de paysagiste. En revenant sur son parcours et en partageant ses convictions, Michel Corajoud nous livre en effet sa «façon de faire » du paysage. Que fait le paysagiste et surtout comment faitil ? C'est à ces questions que l'auteur répond dans cet ouvrage.

3 «Je dessine en ce moment la ligne droite d'un chemin sur le travers d'une pente douce $^{3}$.» écrit Michel Corajoud qui nous explique ensuite comment cet exemple modeste mobilise en réalité un grand savoir-faire et est un acte décisif dans la structure 
du paysage futur. À travers des situations concrètes de projets, Michel Corajoud montre en quoi le paysage est un art singulier. "Le paysage, écrit-il, est un art qui se fonde dans le sol » [...] « un art fondé sur l'antériorité » [...] « le paysage ne se fonde pas par points, il engage toute la surface, et l'on peut dire, qu'à cet égard, il est un art de la propagation ${ }^{4} »$.

4 Les textes ne se succèdent pas dans l'ordre chronologique, mais sont regroupés par thématiques : fondations, façons de faire, filiations, projets, lieux, l'horizon, enseigner le paysage. Ces grands chapitres sont chacun introduits par un préambule recontextualisant les textes. Sont évoqués tour à tour de célèbres projets comme le parc du Sausset, le parc de Gerland, la Cité internationale de Lyon, des études comme celle sur le centre-ville de Montreuil ou des concours perdus comme celui du parc Jules-Verne à Amiens... Ces retours sur expériences laissent apparaître l'élaboration progressive d'une pensée et fait place aussi à l'autocritique d'une pratique, notamment de ses premières réalisations au côté de l'AUA ${ }^{5}$. Ils permettent de suivre le cheminement de l'auteur au fil de ses réalisations depuis la « révélation» du parc du Sausset faisant prendre conscience à l'auteur de l'importance de la mémoire du site, jusqu'aux récents jardins d'Éole où le paysagiste a particulièrement considéré les usages.

5 Mais c'est aussi au fil de ses rencontres que la posture du paysagiste évolue et notamment sa celle avec Jacques Simon au côté duquel il s'initie à la pratique de la transformation des paysages. Son expérience d'enseignement interdisciplinaire à l'Institut d'architecture de l'université de Genève semble aussi avoir été un riche moment d'échanges avec des philosophes (Jean-Marc Besse, Gilles Tiberghien, Sébastien Marot), des historiens (André Corboz), et des architectes (Bernardo Secchi, Georges Descombes, Alain Léveillé, Marcellin Barthassat). Mais parmi les maîtres de Michel Corajoud, il faut surtout citer le grand Le Nôtre. "Le plus sûr de mes enseignants ${ }^{6}$ ", dit-il.

De Le Nôtre il est beaucoup question dans cet ouvrage, notamment dans « Versailles : lecture d'un jardin ", un texte extrait d'une recherche commune de Jacques Coulon, Marie-Hélène Lauze et Michel Corajoud en 1982. Cette étude sur le parc de Versailles est intéressante à plus d'un titre, notamment parce qu'elle est exemplaire de ce que peut être une méthode de recherche résolument paysagiste. Un travail au caractère exploratoire, qui utilise des méthodes proches de celles utilisées dans les démarches de projet et qui s'appuie sur la matérialité du jardin.

7 Au final, la relecture groupée de ces textes de nature très hétérogène (lettres aux étudiants, texte de présentation proposé au jury du grand prix de l'urbanisme, programme pédagogique...) donne à voir une pensée très cohérente et nous livre les concepts clefs de l'auteur. L'horizon, le sol, la mémoire, l'épaisseur sont devenus aujourd'hui des notions fondatrices pour les paysagistes, que l'on peut, grâce à ces textes, restituer à Michel Corajoud. L'ouvrage, bien sûr, appelle quand même au débat car la diversification des pratiques et des formations n'amène pas tous les paysagistes à penser leurs pratiques à la façon de Michel Corajoud. 


\section{NOTES}

1. Proszynska, V. (sous la dir. de), Michel Corajoud, paysagiste, Paris/Versailles, Paris/Versailles, Hartmann Édition/École nationale supérieure du paysage, coll. « Visage », 2000.

2. Dagognet, F. (sous la dir. de), Mort du paysage? Philosophie et Esthétique du paysage, Seyssel, Éditions Champs Vallon, Coll. « Milieux », 1982.

3. Corajoud, M. Le Paysage, c'est l'endroit où le ciel et la terre se touchent, Arles/Versailles, Actes-sud/ ENSP, 2010, p. 47.

4. Ibid., p. 40-41.

5. Atelier d'urbanisme et d'architecture.

6. Corajoud, M. Le Paysage, c'est l'endroit où le ciel et la terre se touchent, op. cit., p. 76.

\section{INDEX}

Mots-clés : paysage, paysagiste, projet de paysage, horizon, pédagogie

Keywords : landscape, landscape architect, landscape project, skyline, education

\section{AUTEUR}

SONIA KERAVEL

Sonia Keravel est paysagiste, enseignante chercheuse à l'École nationale supérieure du paysage de Versailles.

s.keravel[at]ecole-paysage[dot]fr 